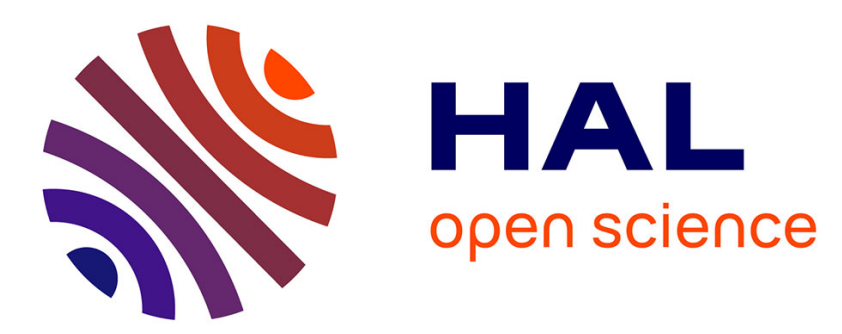

\title{
Detection of iron atoms by emission spectroscopy and laser-induced fluorescence in solid propellant flames
}

\author{
G. Vilmart, N. Dorval, M. Orain, D. Lambert, Rodolphe Devillers, Y. \\ Fabignon, B. Attal-Trétout, A. Bresson
}

\section{- To cite this version:}

G. Vilmart, N. Dorval, M. Orain, D. Lambert, Rodolphe Devillers, et al.. Detection of iron atoms by emission spectroscopy and laser-induced fluorescence in solid propellant flames. Applied optics, 2018, 57 (14), pp.3817-3828. 10.1364/AO.57.003817 . hal-01852507

\section{HAL Id: hal-01852507 \\ https://hal.science/hal-01852507}

Submitted on 16 Jul 2021

HAL is a multi-disciplinary open access archive for the deposit and dissemination of scientific research documents, whether they are published or not. The documents may come from teaching and research institutions in France or abroad, or from public or private research centers.
L'archive ouverte pluridisciplinaire $\mathbf{H A L}$, est destinée au dépôt et à la diffusion de documents scientifiques de niveau recherche, publiés ou non, émanant des établissements d'enseignement et de recherche français ou étrangers, des laboratoires publics ou privés. 


\title{
Detection of iron atoms by emission spectroscopy and laser-induced fluorescence in solid propellant flames
}

\author{
G. Vilmart, N. Dorval, ${ }^{*}$ M. Orain, D. Lambert, R. Devillers, Y. Fabignon, \\ B. Attal-Tretout, and A. Bresson \\ ONERA-The French Aerospace Lab, F-91761 Palaiseau, France \\ *Corresponding author: nelly.dorval@onera.fr
}

\begin{abstract}
Planar laser-induced fluorescence on atomic iron is investigated in this paper, and a measurement strategy is proposed to monitor the fluorescence of iron atoms with good sensitivity. A model is proposed to fit the experimental fluorescence spectra, and good agreement is found between simulated and experimental spectra. Emission and laser-induced fluorescence measurements are performed in the flames of ammonium perchlorate composite propellants containing iron-based catalysts. A fluorescence signal from iron atoms after excitation at $248 \mathrm{~nm}$ is observed for the first time in propellant flames. Images of the spatial distribution of iron atoms are recorded in the flame in which turbulent structures are generated. Iron fluorescence is detected up to $1.0 \mathrm{MPa}$, which opens the way to application in propellant combustion.
\end{abstract}

\section{INTRODUCTION}

Performing optical diagnostics in high-pressure solid propellant combustion remains a challenge. Indeed, in industrial propellants, especially those based on ammonium perchlorate (AP) with a polybutadiene binder (e.g., hydroxyl-terminated polybutadiene $[\mathrm{HTPB}])$, the combustion process leads to ultrahigh luminosity of the flame and large continuous emission background. Background emission is known to originate from (i) blackbody radiation of the hot condensed particles ejected from the surface of the burning propellant (soot particles and/ or alumina particles in the case of an aluminized propellant), (ii) spontaneous emission of the excited species produced by the flame (atoms and radicals), and (iii) chemiluminescence resulting from recombination reactions. Moreover, the spontaneous emission of metallic atoms pertaining to the propellant and originating from their excited states may also contribute to this background. Such a high-pressure, high-luminosity, and heavily particle-laden environment makes optical measurements difficult. Extensive reviews of optical methods applied to solid propellant flames have been reported by Parr and HansonParr [1,2]. Line-of-sight optical techniques such as emission $[3,4]$, UV/visible [5,6], midinfrared [7], and Fourier transform infrared (FTIR) [8] absorption spectroscopies have been used to measure temperature and concentration profiles in these flames. Significant effort was devoted to improve performances, in particular in terms of spatial resolution and signal-to-noise ratio. Laser-based techniques such as spontaneous Raman spectroscopy [9], coherent anti-Stokes Raman scattering (CARS) $[10,11]$, and laser-induced fluorescence (LIF) $[2,9,12-16]$ have also been used. The LIF technique was first applied by Edwards et al. [12] to investigate the flame of a monopropellant (HMX) and of an AP/HTPB propellant up to $3.5 \mathrm{MPa}$. The authors pointed out (1) the difficulty to extract the LIF signal from the intense laser scattering by condensed particles and from the continuous background emission, (2) strong laser beam attenuation and fluorescence trapping in the dense medium, and (3) the challenge to account for the pressuredependent quenching of LIF signal originating from radicals $(\mathrm{OH}, \mathrm{CN}, \mathrm{CH} \ldots)$ so as to obtain quantitative information. Later on, planar laser-induced fluorescence (PLIF) was applied by Parr et al. in various representative flames (for AP/binder sandwich structure), but only a few measurements were performed in real propellant flames [2,9]. LIF signals from several radicals were monitored (e.g., $\mathrm{CN}, \mathrm{NH}, \mathrm{NO}, \mathrm{OH}$ ), and temperature was retrieved from the Boltzmann distribution of population in $\mathrm{OH}$ manifold of levels. More recently, OH-PLIF was used at $5 \mathrm{kHz}$ by Hedman et al. $[15,16]$ to investigate the combustion process of a bimodal AP/binder propellant (from 0.1 to 1.2 MPa). Metal additives are commonly used as burning catalysts in propellant formulation. Therefore, our purpose is to 
probe the metallic atoms themselves. As a matter of fact, they are highly efficient fluorescence emitters allowing the investigation of the flame because they have stronger optical transition moments than molecules.

Iron atoms are present in ballistic additives such as ferrocenic derivative-type catalysts, e.g., butacene (registered trade mark of Airbus Safran Launchers) or iron oxide $\left(\mathrm{Fe}_{2} \mathrm{O}_{3}\right)$. As a result, in the present study, iron seems a good candidate to investigate the hot flow. It can be probed either at the microscopic scale in the hot plume region located close to the propellant surface or at macroscopic scale to follow a shear layer zone inside a vortex, for example. Few papers deal with LIF detection of iron atoms in reactive media. Fe-PLIF was used by Kitagawa et al. [17] to investigate a propane/air flame at low temperature. $\mathrm{Fe}$ and $\mathrm{FeO}$ profiles were recorded using a two-color PLIF system. More recently, Hecht et al. [18] measured the iron distribution during iron-oxide nanoparticles synthesis in a reactor based on lowpressure $(3 \mathrm{kPa}) \mathrm{H}_{2} / \mathrm{O}_{2} /$ Ar flame.

The motivation of our work originates from previous experiments performed in a cold gas flow, above a porous plate to feature simplified, yet realistic, rocket engine geometry [19]. In that previous study, acetone PLIF was performed to visualize parietal vortex shedding by seeding the flow with acetone vapor. As a result, there was a need to develop a PLIF technique able to provide similar information in combustion. Present experiments show that fluorescence signals from iron atoms can easily be detected, whereas acetone is decomposed at high temperature.

Finally, spectroscopy of metallic species was also studied in detail in our laboratory for $\mathrm{Ni}, \mathrm{Co}, \mathrm{Fe}$, and $\mathrm{Al}$ [20-22].

In the present paper, our goal is to demonstrate diagnostic capabilities on iron atoms for in situ investigation of solid propellant combustion. The laser excitation at $248 \mathrm{~nm}$ is generated by a $\mathrm{KrF}$ excimer laser and is combined with a detection window at $300 \mathrm{~nm}$. Details about the experimental setup are given in Section 2. A preliminary investigation of AP/HTPB propellant combustion is done by means of emission spectroscopy in the $270-410 \mathrm{~nm}$ range (Section 3). A model is developed to describe the behavior of the iron atoms' LIF signal [20] (Section 4). Fe spectroscopy is carefully investigated in the specific excitation/detection scheme previously chosen [21]. The fluorescence measurements are then presented in Section 5. The experimental study is undertaken first in a laser vaporization reactor to record the fluorescence spectra. The dispersed fluorescence spectral profile exhibits direct fluorescence lines and spurious features, which are weak indirect fluorescence lines due to the internal relaxation process. The spectrum, which is recorded by scanning the spectrometer slit, is fitted to the theoretical profile. The fitting procedure is relying on the previously known spectroscopic parameters of the Fe manifold of levels, to calculate the LIF spectrum with due account for all collisional deactivation processes. It thus allows identification of the cascading transitions experienced by the iron atoms after $248 \mathrm{~nm}$ excitation and determination of the relevant collisional parameters. Fe-PLIF images are also recorded in catalyzed propellant flames at 0.3 and $1.0 \mathrm{MPa}$ without and with a transversal air flow (Section 5). To our knowledge, it is the first in situ observation of such iron signatures in solid propellant combustion.

\section{EXPERIMENTAL SETUP}

\section{A. Laser Vaporization Reactor}

Fluorescence point measurements are carried out in the vaporized plume of iron-containing carbon targets. The target is heated inside a helium flow by a continuous-wave $\mathrm{CO}_{2}$ laser $(800 \mathrm{~W}$ output power) at $300 \mathrm{hPa}$ total pressure and at steadystate conditions at a target temperature [21,22]. Carbon targets containing iron powder (concentration of 2 at. \% or impurities) are vaporized. The reactor is equipped with UV fused silica windows.

Experiments are carried out with a $\mathrm{KrF}$ excimer laser (PSX501 , Neweks) delivering pulses of $5 \mathrm{~ns}$ in duration and $5 \mathrm{~mJ}$ in energy at $248 \mathrm{~nm}$ and $25 \mathrm{~Hz}$ repetition rate. The laser beam is focused with a lens of $300 \mathrm{~mm}$ focal length. The lens-target distance is adjusted to obtain a laser area of approximately $6 \mathrm{~mm} \times 6 \mathrm{~mm}$ at the probe volume. Measurements are performed $3 \mathrm{~mm}$ above the target surface at $2000 \mathrm{~K}$, as previously measured by CARS [21]. Detection and acquisition of the signal are described elsewhere [21,22]. It consists of a UV fused silica collection lens (diameter: $25 \mathrm{~mm}$; focal length: $75 \mathrm{~mm}$ ), which is used to image the signal in a silica optical fiber (HCG M1000T, multimode step-index, core diameter: $1 \mathrm{~mm}$ ) with a magnification of 1 . The fiber is connected to a spectrometer (Jobin-Yvon H20 UV, focal length: $200 \mathrm{~mm}, f / 4.2$; dispersion: $4 \mathrm{~nm} / \mathrm{mm}$ ) equipped with a photomultiplier tube (XP2018B, Photonis). The emission spectrum of a deuterium lamp is recorded to measure the spectral apparatus function. The fluorescence spectrum is then corrected for that spectral response of the detection system. The output signal is timeintegrated over a gate of $200 \mathrm{~ns}$ by means of a Boxcar averager (SR250 \& SR280, Stanford Research Systems). The laser linewidth is $0.35 \mathrm{~nm}$, and the spectral resolution of the detection system is $4 \mathrm{~nm}$. Because the hot flow is mainly composed of carbon nanoparticles, no spurious laser scattering is detected apart from the fluorescence signal.

\section{B. Propellant Flame}

A variant of the standard window bomb (Fig. 1) is used for solid propellant combustion [23]. Pressurization of the vessel is realized using dry air. Propellant samples are ignited by means of a $\mathrm{CO}_{2}$ laser entering from the top of the vessel ( $\mathrm{ZnSe}$ window). A heat flux density of about $100 \mathrm{~kW} / \mathrm{cm}^{2}$ is obtained with a laser pulse duration of typically $100 \mathrm{~ms}$. The vessel is equipped with three UV fused silica windows. The air flow, which is introduced in order to induce vortices, is kept constant at $5 \mathrm{~m} / \mathrm{s}$, corresponding to a mass flow rate of $60 \mathrm{~g} / \mathrm{s}$, using a sonic nozzle $(10 \mathrm{~mm}$ in diameter) at the exit of the vessel. Difference between the pressure upstream (vessel inlet) and downstream (nozzle) is kept constant at $0.17 \mathrm{MPa}$. Composition of solid propellant and operating conditions is given in Table 1.

The AP-based composite propellants are manufactured by ONERA. A growing interest was expressed by Airbus Safran Launchers to incorporate nano-sized catalysts into the propellant to improve its performances. A lower melting temperature and increased catalytic activity results in a faster burning velocity thanks to the high specific-surface area achieved with nanoparticles. Within this framework, carbon-coated iron nanoparticles have been tested to estimate their efficiency as 


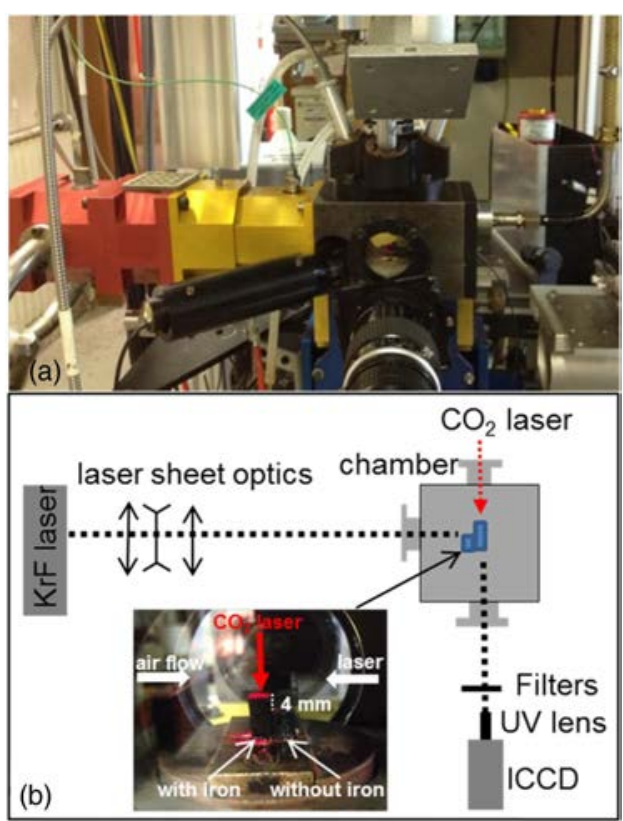

Fig. 1. Experimental setup. (a) Test rig of solid propellant flames investigation. (b) PLIF experiment.

catalysts [24]. Both Fe-C nanoparticles produced by our arc discharge reactor [24] and commercial ones (PlasmaChem $\mathrm{GmbH}$ ) were incorporated into our propellant. Home-made nanoparticles are 12 to $100 \mathrm{~nm}$ in diameter, and the iron content is 30 wt. \%. By contrast, commercial nanoparticles are 5 to $500 \mathrm{~nm}$ in diameter, and the iron content is 80 wt. \%.

Emission measurements are performed in the UV range to provide overall information about excited species produced in the flame. Light is collected through one of the windows (50 $\mathrm{mm}$ in diameter) by a spherical UV lens (focal length: $100 \mathrm{~mm}$ ), imaging the flame onto the entrance slit (width: $100 \mu \mathrm{m}$; height: $15 \mathrm{~mm}$ ) of a spectrometer (SPEX 270M, Jobin Yvon) coupled to an ICCD camera (HSICCD 576G/ BT, $576 \times 384$ pixels, Princeton Instruments). The gate width of the camera is adjusted between 5 and $200 \mu$ s. The entrance slit of the spectrometer is oriented vertically with respect to the horizontal surface of the propellant. Light is thus spatially collected over the full height of the flame. The 600 groves/ $\mathrm{mm}$ grating of the spectrometer is blazed at $400 \mathrm{~nm}$. The framing rate of the CCD array is $50 \mathrm{~Hz}$ in full binning (over
384 pixels). The collected light is then dispersed over the CCD length ( 576 pixels), i.e., over $80 \mathrm{~nm}$. Binning $3 \times$ over 576 pixels leads to a spectral resolution of $0.417 \mathrm{~nm} /$ pixel. Spectra are recorded during two successive runs, in order to cover the 270 $350 \mathrm{~nm}$ and the $330-410 \mathrm{~nm}$ ranges on the CCD spectral width. Few tens of spectra are averaged to improve the quality of the final spectrum and leads to unambiguous assignment of the persistent features. Finally, raw spectra are corrected for the spectral response of the detection system (apparatus function) thanks to a previous calibration procedure. The emission spectrum of a deuterium lamp is recorded to measure the spectral apparatus function. In addition, the UV lines of an $\mathrm{Hg}$-Ar lamp are used to perform absolute wavelength calibration.

The LIF setup is shown in Fig. 1. A KrF excimer laser at $248 \mathrm{~nm}$ is used for excitation (Section 2.1). Final energy per pulse is about $4 \mathrm{~mJ}$ at the probe volume. A laser sheet is formed using a combination of two cylindrical lenses (-20 $\mathrm{mm}$ and $150 \mathrm{~mm}$ focal lengths) and a spherical lens (500 mm focal length). The laser sheet is $20 \mathrm{~mm}$ in height and $2.5 \mathrm{~mm}$ in thickness, which corresponds to half the thickness of propellant samples. Fluorescence is recorded using a 16-bit ICCD camera (PIMAX2, Roper Scientific). The temporal gate is set to 50 ns. The CCD array is $1024 \times 1024$ pixels, and the framing rate is $3 \mathrm{~Hz}$. Light is transmitted to the ICCD camera through one of the windows of the vessel (at $90^{\circ}$ from the laser sheet) and an achromatic UV lens (aperture: $f / 4.1$, focal length: $94 \mathrm{~mm}$, Cerco). This way, a $32 \mathrm{~mm} \times 32 \mathrm{~mm}$ area is imaged onto the CCD array, providing a spatial resolution of $31 \mu \mathrm{m}$ per pixel. An UV broadband filter (DUG11X, Schott, ITOS $\mathrm{GmbH}$ ) and a bandpass filter centered at $302 \mathrm{~nm}$ (10 $\mathrm{nm}$ in width, ZBPA300, Asahi) are used on the detection path. This set of filters provides efficient attenuation of the visible light in order to allow extinction of laser scattering by particles and smoke.

Raw fluorescence images are corrected for the camera electronic noise, laser scattering, reflections, and spatial nonuniformity of the laser sheet. In a first step, an average background image is recorded with the laser on and no combustion. Subtraction of this image from the raw image allows suppressing laser scattering and other background luminosity from the measurement. Then, a mean fluorescence image is recorded in a cell of acetone vapor at room temperature placed at the probe volume. Background-subtracted Fe-PLIF images are thus divided by the mean profile of acetone fluorescence to correct iron fluorescence images for the spatial inhomogeneity of the

Table 1. Composition and Size (Height $\times$ Length $\times$ Thickness) of the Solid Propellants and Operating Conditions

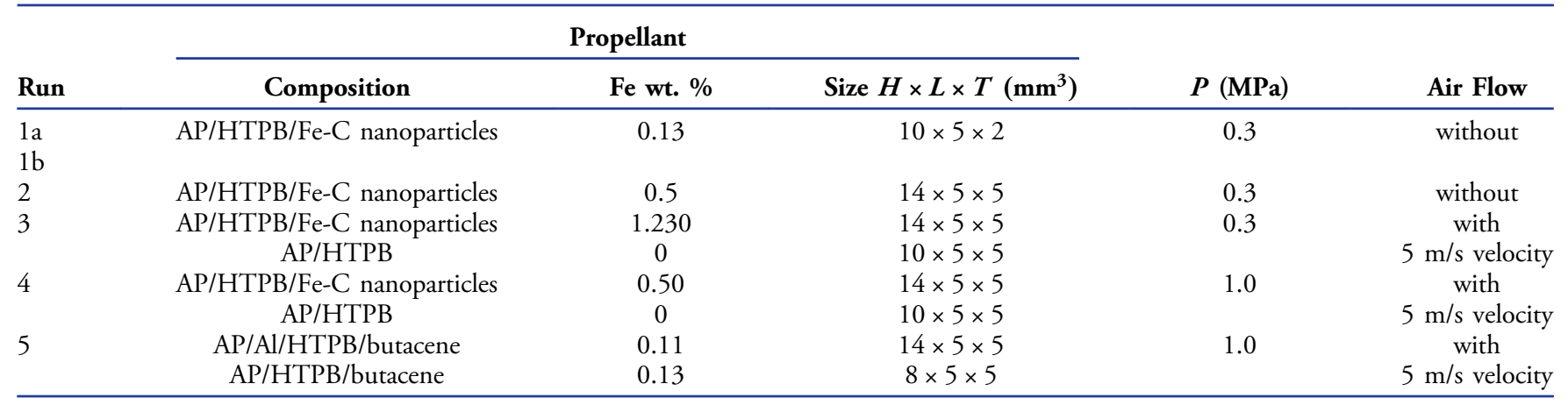


laser sheet. Correction for the laser fluctuations from shotto-shot (stability $\sim 3 \%$ ) is not done in the present treatment.

\section{EMISSION SPECTROSCOPY}

Emission spectra are recorded during combustion of propellants in order to identify the main emitting species. Figure 2 (in Table 1, Runs 1a, 1b) shows emission spectra recorded at $0.3 \mathrm{MPa}$ in the flames of $\mathrm{AP} / \mathrm{HTPB}$ propellants doped with $\mathrm{Fe}-\mathrm{C}$ nanoparticles.

Fe spectrum is calculated using the Kurucz database [25] and is shown in Fig. 2; it takes into account 101 lines involving the lower levels between 0 and $8155 \mathrm{~cm}^{-1}$ and upper levels ranging from 25900 to $36000 \mathrm{~cm}^{-1}$. The intensity distribution is calculated assuming thermal equilibrium and a temperature of about $2500 \mathrm{~K}$ according to vertical spatial averaging in AP/ HPBT flame [26]. The population in each excited state is calculated from the Boltzmann distribution. In Fig. 2(a), OH $\left(A^{2} \Sigma^{+}-X^{2} \Pi\right)$ bands at $309 \mathrm{~nm}$ appear on a large continuum background, with a signal-to-noise (SNR) ratio of 2 . A sporadic peak is observed at $336 \mathrm{~nm}$, which is likely due to the $\mathrm{NH}$
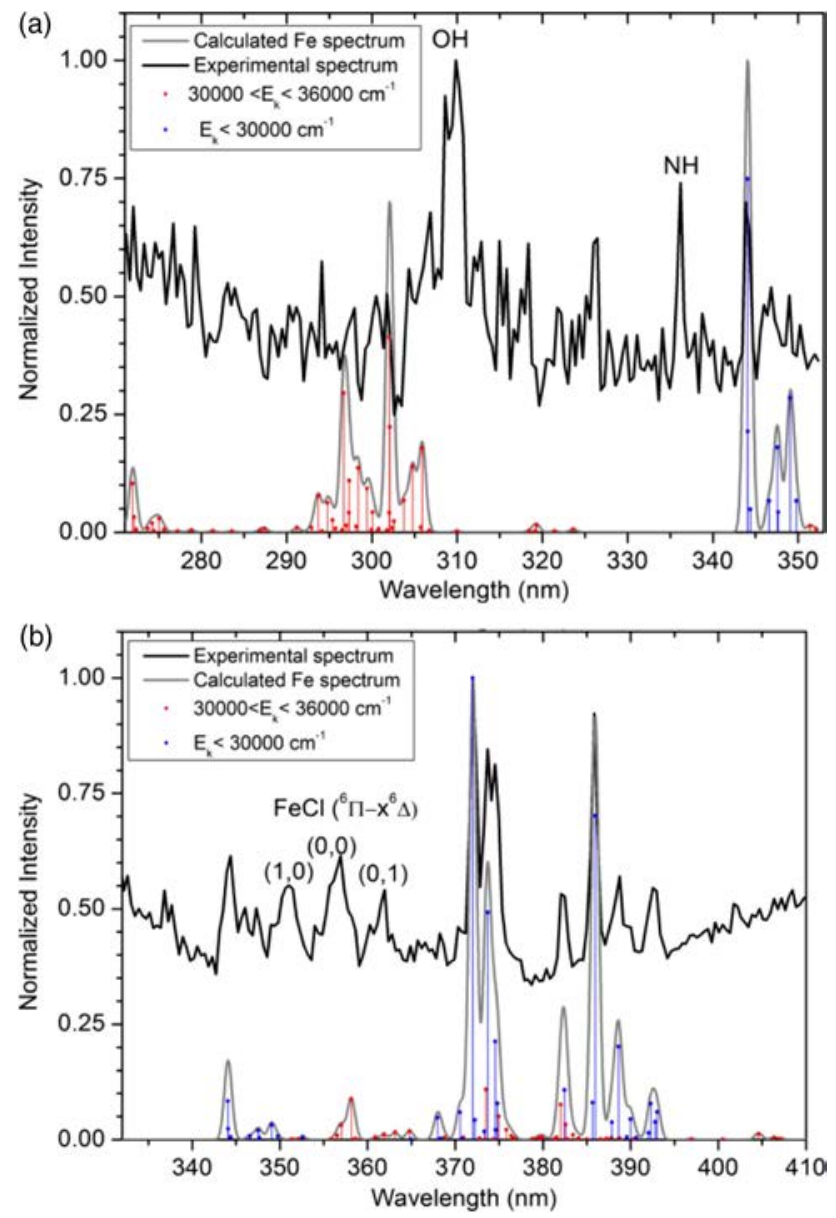

Fig. 2. Emission spectra recorded above the surface of an AP/ HTPB propellant sample with $\mathrm{Fe}-\mathrm{C}$ nanoparticles (Runs 1a and 1b). The spectral windows are (a) $270-355 \mathrm{~nm}$, (b) $330-410 \mathrm{~nm}$. The camera exposure time is $200 \mu \mathrm{s}$. The calculated emission spectra of $\mathrm{Fe}$ atom at $2500 \mathrm{~K}$ are displayed for comparison. The Fe lines are indicated by the Dirac peaks. $E_{k}$ is the energy of the upper levels involved in the calculated lines. radical. The $\mathrm{OH}$ and $\mathrm{NH}$ intensities are similar. Among the many lines of iron, one located at $344 \mathrm{~nm}$ is clearly visible and persistent, whereas, at shorter wavelengths, lines originating from higher levels are not clearly observed. The strongest $\mathrm{Fe}$ lines at 372-375, 382, 386, 388, and $393 \mathrm{~nm}$ are observed with a SNR between 2 and 3 in Fig. 2(b). Figure 2 clearly shows the dominant contribution of iron catalysts to emission spectra. If the pressure is increased beyond 0.3 $\mathrm{MPa}$, iron is still observed because of its strong emission transition probability $\left(1.6 \times 10^{7} \mathrm{~s}^{-1}\right.$ at $372 \mathrm{~nm}$ for Fe [25] against $6 \times 10^{5} \mathrm{~s}^{-1}$ at $309 \mathrm{~nm}$ for $\mathrm{OH}$ [27]). At high pressure, $\mathrm{OH}$ bands are swamped into the increasing background. It may also be noted that three molecular emission bands are observed at 351,357, and $362 \mathrm{~nm}$. These are assigned to a sequence of vibrational bands of $\mathrm{FeCl}$ belonging to the $\left({ }^{6} \Pi-X^{6} \Delta\right)$ system near $357 \mathrm{~nm}$ [28-30]. The chemistry of the flame is thus producing chlorine radicals. Inside that sequence, frequency spacing between adjacent bands lead to a harmonic vibrational constant of $400 \mathrm{~cm}^{-1}$, which is in agreement with the value of $408 \mathrm{~cm}^{-1}$ found for the $X^{6} \Delta$ state $\left(429 \mathrm{~cm}^{-1}\right.$ for the ${ }^{6} \Pi$ state $)$ in [30].

This emission investigation of a propellant flame thus provided first information about the spectral content observed when an iron catalyst is used. The LIF technique is then used in a second step to provide a better signal-to-background ratio with high spatial and temporal resolutions. Preliminary fluorescence spectroscopic measurements of iron atoms are done in well-controlled conditions (in laser vaporization reactor) before application to a propellant flame. We will first describe the theoretical model of the LIF process that is developed to account for the radiative and the nonradiative deactivation pathways experienced by iron atoms in excited states.

\section{MODEL}

Theoretically, the fluorescence signal of a single spectral line depends on the amplitude of the line. It is linked to its coefficient of spontaneous emission $\left(A_{j i}\right)$ to the population density of the excited level $\left(N_{j}\right)$ and to the overlap integral $\left(\int \phi(\nu) \Phi(\nu) \mathrm{d} \nu\right)$ between its spectral profile $\phi$ and the spectral profile of the detector $\Phi$ [31]. Note that we are using the convention that the integral of any atomic line is equal to 1 $\left(\int \phi(\nu) \mathrm{d} \nu=1\right)$ and that $\Phi$ is the rectangle function centered on the line. Here, because the atomic spectral width is much narrower than the apparatus function of the spectrometer (a few pm against $4 \mathrm{~nm}$ ), we can consider that $\phi \times \Phi \approx \phi$, thus leading to $\int \phi(\nu) \Phi(\nu) \mathrm{d} \nu=1$. The signal is thus independent of the line width and depends only on its peak amplitude.

Thus, we need first to calculate the population density of the level, taking into account the collisional energy transfers. Then, we calculate the line broadening due to the Doppler effect and the collisions (pressure broadening), and the resulting Voigt profile is convoluted by the apparatus function of the spectrometer.

\section{A. Calculation of Population Density}

The model is similar to the one previously developed for aluminum atoms [20]. It calculates the population density of $\mathrm{Fe}$ in each state as a function of time, starting from the kinetic rate equations, as described by Daily [31]. The model involves $n$ 
first-order coupled differential rate equations describing the multilevel atom. The temporal evolution of the population density $N_{j}$ of state $j$ is given by the rate equation [Eq. (1)]:

$$
\begin{aligned}
\frac{d N_{j}}{d t}= & \sum_{i \neq j, W_{i j} \neq 0} W_{i j} N_{i}+\sum_{i>j} A_{i j} N_{i}+\sum_{i \neq j} Q_{i j} N_{i} \\
& \left.-\sum_{i \neq j, W_{j i} \neq 0} W_{j i} N_{j}+\sum_{i<j} A_{j i} N_{j}+\sum_{i \neq j} Q_{j i} N_{j}\right) .
\end{aligned}
$$

It takes into account the gain in population density (three first terms) due to

- absorption of laser photons from the lower states for $i<j$, or stimulated emission from upper states for $j>i\left(W_{i j}\right.$, absorption/stimulated emission rate in $\mathrm{s}^{-1}$ );

- radiative transfers from the upper states for $i>j$ $\left(A_{i j}\right.$, Einstein coefficient for spontaneous emission in $\left.\mathrm{s}^{-1}\right)$;

- nonradiative collisional energy transfers, mainly but not only from the upper states, for $i>j\left(Q_{i j}\right.$, rate of collisional energy transfer in $\mathrm{s}^{-1}$ );

and the loss of population density (three last terms) due to

- stimulated emission toward lower states for $i<j$, and absorption of laser photons toward upper states for $j>i\left(W_{j i}\right)$;

- spontaneous emission toward the lower states for $i<$ $j\left(A_{j i}\right)$;

- nonradiative collisional energy tranfsers mainly but not only toward the lower states for $i<j\left(Q_{i j}\right)$.

Laser ionization is neglected because the energy of the laser can only induce one photon transition. The absorption/ stimulated emission rates are calculated from the expression of Hilborn [32] using the transition strengths extracted from the Kurucz database [25]. Even the levels that are not populated by radiative transitions can be populated by collisional energy transfers. Accordingly, calculation has to properly simulate these collisional transfers responsible for the distribution of the population density over all levels. One advantage of the model is that it is not necessary to specify which levels are involved in the spectrum because it is able to determine the levels populated by collisions.

\section{B. Modeling of the Collisional Process}

Our purpose is to predict the influence of collisions (or pressure) on the fluorescence signal. Only the case of inelastic collisions is considered, in which the quantum state of the radiating atom is changed. Furthermore, we disregard the case in which the quantum state of the colliding partner is changed. It means that all the released (or gained) energy is transformed into (or gained from) kinetic energy of the colliding partner.

The relaxation (or excitation) of a level of the radiating iron atom, $\mathrm{Fe}_{i, j}$, following a collision with the colliding molecule (or atom), $M$ can be described by the bimolecular reaction:

$$
\mathrm{Fe}_{i}+M \rightleftharpoons \mathrm{Fe}_{j}+M \text {. }
$$

The speed of the reaction is characterized by the rates of the forward reaction $\left(Q_{i j}\right)$ and the reverse one $\left(Q_{i j}\right)$. The temperature and pressure sensitive rates are given by the product between the number density of the colliders, $[M]$ (molecule $\mathrm{cm}^{-3}$ ), and the collisional transfer rate coefficients, $k$ (molecule $\left.{ }^{-1} \mathrm{~cm}^{3} \mathrm{~s}^{-1}\right)$ :

$$
Q_{i j}(T)=k_{i j}(T)[M] .
$$

It is also useful to introduce the total collisional transfer rate, $Q_{j}^{\text {tot }}$, proportional to the total rate coefficient, $k_{j}^{\text {tot }}$, to represent the population depletion of the level $j$ through collisional energy transfers. It is defined as the sum of all the individual collisional transfer rates $Q_{j i}$ (and rate coefficient $k_{j i}$ ):

$$
Q_{j}^{\text {tot }}=\sum_{i \neq j} Q_{j i}=\sum_{i \neq j} k_{j i}[M]=k_{j}^{\text {tot }}[M] .
$$

Some experimental collisional data can be found in literature $[18,33,34]$. Nizamov and Dagdigian measured the total collisional transfer rate coefficients, $k^{\text {tot }}$, in the $z^{5} D_{J}^{o}$ states $(J=0-4)$ of the Fe atom [33]. The corresponding transitions originating from the ground state $a^{5} D_{J}$ are located in the 382-393 nm range. The $k^{\text {tot }}$ values were obtained for several gas colliders $\left(\mathrm{He}, \mathrm{Ar}, \mathrm{N}_{2}, \mathrm{O}_{2}, \mathrm{H}_{2}\right.$, and $\left.\mathrm{CH}_{4}\right)$ in the range 0.3$20 \mathrm{hPa}$ at room temperature. When collisional partners are molecular gases, $k_{\text {tot }}$ varies from 3 to $8 \times 10^{-10}$ molecule $^{-1} \mathrm{~cm}^{3} \mathrm{~s}^{-1}$ depending on the gas and on the $J$ quantum number. The rate coefficients are approximately 1 order of magnitude lower for $\mathrm{Ar}$ and $\mathrm{He}$ gases. For molecular colliders, the $Q^{\text {tot }}$ rates are calculated to be between 3 and $8 \times 10^{10} \mathrm{~s}^{-1}$ at $300 \mathrm{~K}$ and $1 \mathrm{MPa}$. Goo et al. earlier studied the kinetics of the $z^{3} D_{J}^{o}(J=1-3)$ and $z^{3} F_{J}^{o}(J=2-4)$ states with transitions from the ground state lying between 315 and $325 \mathrm{~nm}$ [34]. The authors measured the values of $k_{\mathrm{tot}}$ at $300 \mathrm{hPa}$ of $\mathrm{He}$ or $\mathrm{Ar}$ gas and room temperature. Their values are found to be 1 order of magnitude higher than for the other states $z^{5} D_{J}^{o}$ states [33] for the same noble gas colliders with $k_{\text {tot }}$ from 1.57 to $6.57 \times 10^{-10}$ molecule $^{-1} \mathrm{~cm}^{3} \mathrm{~s}^{-1}$. Nizamov and Dagdigian explained this discrepancy by a possible collisional mixing between the neighboring states $z^{3} D^{o}$ and $z^{3} F^{o}$ [33]. Hecht et al. [18] have measured the reduction of the $w^{5} F_{4}^{o}$ lifetime involved in the $w^{5} F_{4}^{o}-a^{5} D_{4}$ transition at $225 \mathrm{~nm}$ from $23 \mathrm{~ns}$ in vacuum to $6.4 \pm 3 \mathrm{~ns}$ in a flame at $1200 \mathrm{~K}$ and $30 \mathrm{kPa}$ [25]. This leads to a rate coefficient of $k^{\text {tot }}=(6.25 \pm 4) \times 10^{-10}$ molecule $\mathrm{e}^{-1} \mathrm{~cm}^{3} \mathrm{~s}^{-1}$ and a quenching rate $Q^{\text {tot }}=(1.5 \pm 1) \times 10^{10} \mathrm{~s}^{-1}$ at $1 \mathrm{MPa}$ and $1200 \mathrm{~K}$. All rate coefficients $k^{\text {tot }}$ retrieved from $[18,33,34]$ are given in Table 2.

Experimental collisional transfer rates are known only for a few states. The rate coefficients depend on temperature, nature of the colliding partner, close lying states (because of possible collisional mixing), and nature of the quantum configuration of the state ( $J$ dependent). Thus, it is not possible to use the $k$ coefficient of one state to characterize the collisional transfer of another state. Furthermore, experimental determination of transfer rates by measurement of the fluorescence decay time is not always possible.

We thus undertake a calculation of the rate coefficients. Several theories of different complexity and accuracy describe the collisional energy transfers. The full quantum mechanical treatment based upon the calculation of the relaxation matrix by the scattering matrix [36], and the determination of the potential energy surfaces in the transition state theory with ab initio methods (e.g., Hartree-Fock method [37]) are too complicated and time-consuming for the present study. The much simpler classical theory of collisions relying on the basic assumptions of the kinetic theory of gases is used in this 
Table 2. Total Collisional Transfer Rate Coefficients, $k_{\text {tot }}$, (unit: $10^{-10}$ molecule ${ }^{-1} \mathrm{~cm}^{3} \mathrm{~s}^{-1}$ ) Found in Literature, $\tau$ is the Radiative Lifetime of the State from $[25,35]$

\begin{tabular}{|c|c|c|c|c|c|c|c|c|c|c|c|c|}
\hline State & $J$ & Energy $\left(\mathrm{cm}^{-1}\right)$ & $\tau(\mathbf{n s})$ & \multicolumn{7}{|c|}{$k^{\text {tot }}$} & $T(\mathrm{~K})$ & Ref. \\
\hline \multirow[t]{4}{*}{$z^{5} D^{o}$} & 4 & 25899.987 & 80 & 0.36 & 1.35 & 3.82 & 4.43 & 8.28 & 4.15 & - & 300 & {$[33]$} \\
\hline & 2 & 26339.691 & 89 & 0.56 & 0.77 & 3.65 & 4.56 & 8.33 & 5.2 & - & & \\
\hline & 1 & 26479.376 & 79 & 0.96 & 0.47 & 3.18 & 3.65 & 7.34 & 6.25 & - & & \\
\hline & 0 & 26550.476 & 89 & 0.48 & 0.37 & 2.71 & 3.49 & 6.38 & 4.93 & - & & \\
\hline$z^{3} D^{o}$ & 1 & 31937.316 & 332 & 3.4 & 1.57 & - & - & - & - & - & & \\
\hline \multirow[t]{3}{*}{$z^{3} F^{o}$} & 4 & 31307.243 & 754 & 4.93 & 4.64 & - & - & - & - & - & 300 & [34] \\
\hline & 3 & 31805.067 & 841 & 4.1 & 3.03 & - & - & - & - & - & & \\
\hline & 2 & 32133.986 & 1200 & 2.1 & 6.5 & - & - & - & - & - & & \\
\hline \multirow[t]{2}{*}{$w^{5} F^{o}$} & 4 & 44415.07 & 22.9 & - & - & - & - & - & - & $3.21 \pm 2$ & 800 & [18] \\
\hline & & & 22.9 & - & - & - & - & - & - & $6.25 \pm 4$ & 1200 & \\
\hline
\end{tabular}

study [38]. The bimolecular rate coefficient of collisional energy transfer from initial level $i$ to final level $j, k_{i j}$ is expressed as [39]

$$
k_{i j}(T)=q \sqrt{\frac{8 k_{B} T}{\pi \mu}} \sigma e^{-\frac{E_{a}}{k_{B} \cdot T}},
$$

where $q$ is a steric factor (arbitrary factor), $k_{B}$ is the Boltzmann constant, $\mu$ is the reduced mass of the colliders, $\sigma$ is the collisional cross section $\left(\mathrm{cm}^{2}\right), \Delta E_{a}$ is the activation energy $\left(\mathrm{cm}^{-1}\right)$, and $T$ is the temperature $(\mathrm{K})$. The collisional cross section $\sigma$ is defined as

$$
\sigma=\pi\left(r_{\text {pert }}+r_{\mathrm{Fe}}\right)^{2},
$$

where $r_{\text {pert }}$ is the radius of the perturbing collider and $r_{\mathrm{Fe}}$ is the radius of the iron atom. Activation energy, $\Delta E_{a}$, is approximated as the energy gap between the final and initial level $E_{j}-E_{i}$.

The factor $q$ represents the probability that collisions with sufficient energy actually lead to the energy transfer process. It accounts for geometrical limitations and for classical criterion limitations [38]. The selection rules for spin and orbital angular momentum, $\Delta S=0$ and $\Delta L=-1,0,1$ are applied [38]. There is no selection rule for the total angular momentum $J$.

\section{Fe Excitation Scheme}

Figure 3 is showing large manifold of levels involved in the electronic spectrum of iron atoms. Of course, the laser excitation is picking up only some of them in initial and final states $x^{5} F^{o}$ and $a^{5} D$, respectively.

Among the 15 transitions located inside the laser spectral profile (between 247.9 and $248.7 \mathrm{~nm}$ ), two transitions are seen efficiently resonant with the laser in Fig. 4.

The strongest electronic transition $x^{5} F_{5}^{o}-a^{5} D_{4}$ at $248.3271 \mathrm{~nm}$ originates from the ground state. The second transition $x^{5} F_{1}^{o}-a^{5} D_{1}$ at $248.4185 \mathrm{~nm}$, although much weaker, is taken into account in the signal calculation.

Line positions and line strengths are extracted from [25]. The absorption rates $\left(W_{i j}\right)$ are calculated according to the expression of Hilborn [32]. In each line of Fig. 4, the fraction of population in the $i$ level $\left(f_{\text {pop }}\right)$ is calculated according to the Boltzmann equation at $2000 \mathrm{~K}$ ( $2500 \mathrm{~K}$ for propellants) and is

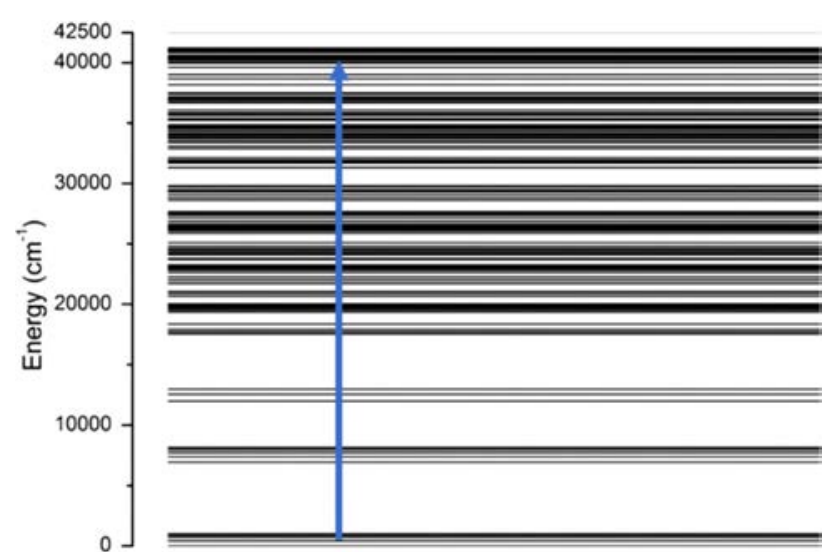

Fig. 3. Energy-level diagram of iron limited to 146 energy levels located below $42500 \mathrm{~cm}^{-1}$. Laser pumping is indicated by the blue line.

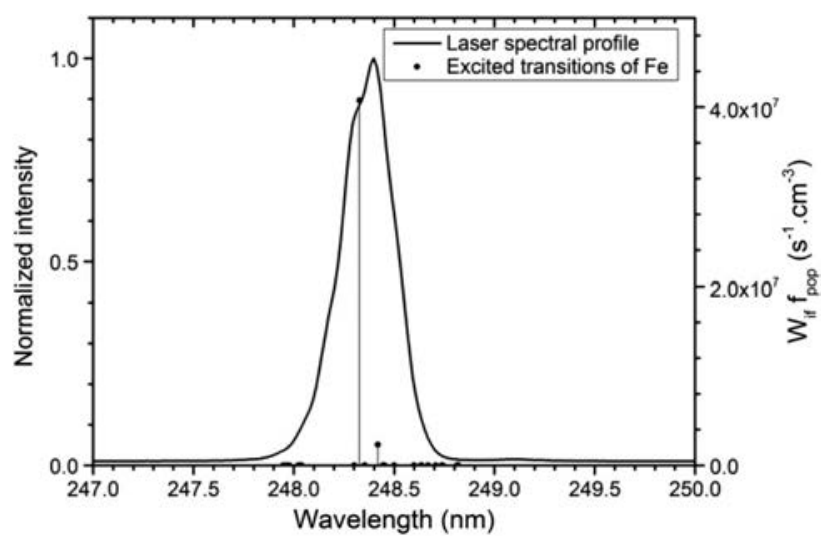

Fig. 4. Recorded spectral profile of the $\mathrm{KrF}$ laser (in normalized intensity) compared with the Dirac peaks of the $\mathrm{Fe}$ lines contained herein whose amplitudes are given by the absorption rates $\left(W_{\text {if }}\right)$ multiplied by the Boltzmann population fraction $\left(f_{\text {pop }}\right)$ at $2000 \mathrm{~K}$. 


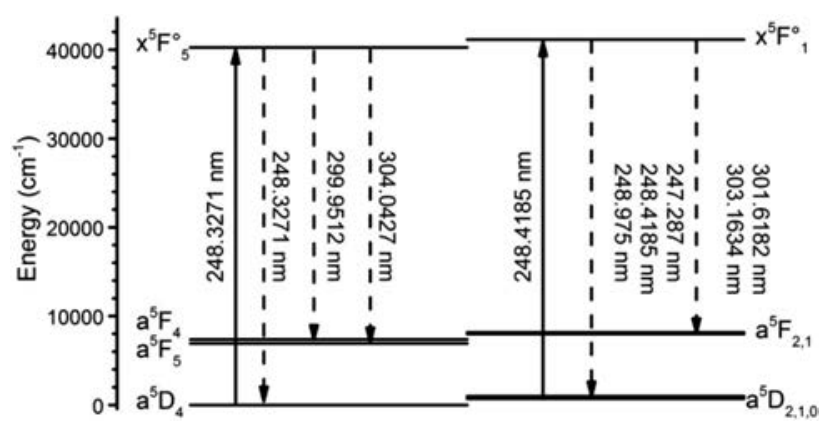

Fig. 5. Energy-level scheme of the eight fluorescence lines (solid lines) induced by laser excitation (dashed lines).

multiplied by the absorption rates $W_{i j}$ with due account for the atomic spectral profile. Let us recall that the laser linewidth is $0.35 \mathrm{~nm}$, which is about 170 times broader than the Doppler linewidth at $2000 \mathrm{~K}$. Collisional width is assumed to be $0.32 \mathrm{~cm}^{-1}$ at $0.03 \mathrm{MPa}$ [40] and increases linearly with pressure.

Figure 5 shows the energy-level scheme of these two resonant transitions, $x^{5} F_{5}^{o}-a^{5} D^{4}$ and $x^{5} F_{1}^{o}-a^{5} D_{1}$.

Two direct fluorescence lines originating from level $x F_{5}^{o}$ occur at $299.9512 \mathrm{~nm}\left(x^{5} F_{5}^{o}-a^{5} F_{5}\right)$ and $304.0427 \mathrm{~nm}$ $\left(x^{5} F_{5}^{o}-a^{5} F_{4}\right)$. From level $x^{5} F_{1}^{o}$, four direct fluorescence pathways are possible at $247.287 \mathrm{~nm}\left(x^{5} F_{1}^{o}-a^{5} D_{2}\right), 248.975 \mathrm{~nm}$ $\left(x^{5} F_{1}^{o}-a^{5} D_{0}\right), 301.6182 \mathrm{~nm}\left(x^{5} F_{1}^{o}-a^{5} F_{2}\right)$, and $303.1634 \mathrm{~nm}$ $\left(x^{5} F_{1}^{o}-a^{5} F_{1}\right)$. Direct and resonant fluorescence lines excited by the $\mathrm{KrF}$ excimer laser, with a total of eight transitions, are thus localized nearby the laser line $(248 \mathrm{~nm})$ and at longer wavelength $(300-304 \mathrm{~nm})$.

\section{RESULTS}

\section{A. LIF Spectroscopy}

\section{Experimental Spectra in a Laser Vaporization Reactor}

In order to select an optimum strategy for the flame study, dispersed fluorescence spectra were recorded in a cw $\mathrm{CO} 2$ laser vaporization reactor, as briefly presented in the previous section [21]. Figure 6 shows the dispersed fluorescence spectrum of iron atoms recorded at $300 \mathrm{hPa}$ and $2000 \mathrm{~K}$ (gas temperature) from a carbon target containing iron impurities.

The spectrum is composed of the resonant fluorescence line at $248 \mathrm{~nm}$ and the direct fluorescence lines at 300 and $304 \mathrm{~nm}$. However, the intensity ratio of the two lines, $248 / 300 \mathrm{~nm}$, is lower than the expected one. Indeed, the experimental ratio is 18 instead of 25 for the theoretical one using the Kurucz's data [25]. Furthermore, unexpected weaker lines located at 250 (in the wing of the $248 \mathrm{~nm}$ line), 275, 285, and $305 \mathrm{~nm}$ are also observed.

We can attribute those spectral unexpected lines to the cascade fluorescence induced by collisional energy transfers (indirect paths), owing to the large number of levels (1732) and transitions (425) of the iron atom [25] in the observed spectral window (Fig. 3). This implies that more levels than the main resonances labeled in Fig. 5 are contributing to the experimental spectrum of Fig. 6.

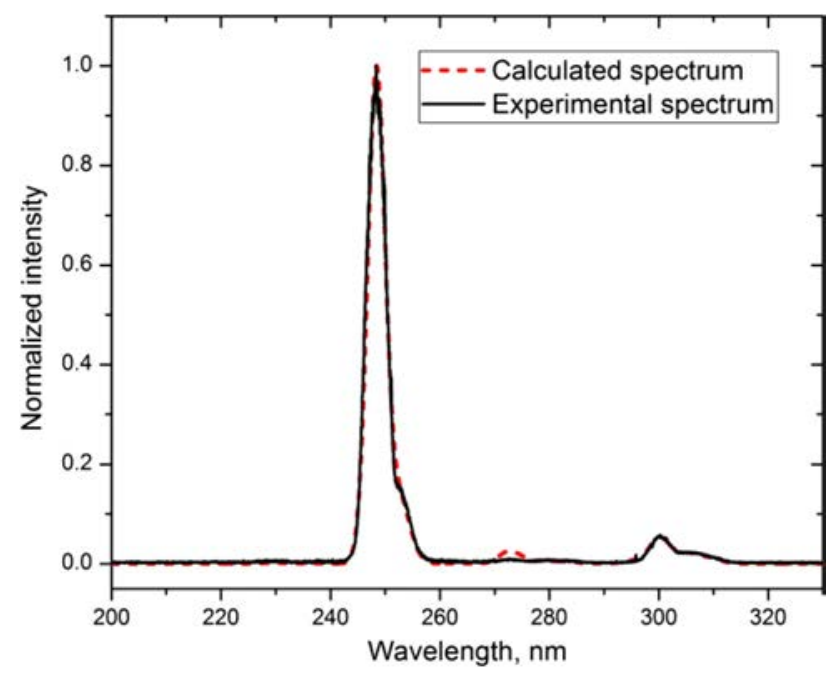

Fig. 6. Experimental fluorescence spectrum recorded at $T=$ $2000 \mathrm{~K}$ (gas temperature) $3 \mathrm{~mm}$ above a carbon target (containing iron impurities at most 0.1 at. \%) vaporized at $3200 \mathrm{~K}$ (target temperature) in a continuous $\mathrm{He}$ flow $(300 \mathrm{hPa}, 50 \mathrm{ml} / \mathrm{s})$. It is compared with a spectrum calculated at $2000 \mathrm{~K}$ and $300 \mathrm{hPa}$.

As previously mentioned, no collisional rate coefficients were available for the upper state $x^{5} F_{5}^{o}$ of the $248.327 \mathrm{~nm}$ transition. Furthermore, measurement of the fluorescence decay time appears difficult owing to the short lifetime of this state (2 ns). Therefore, collisional transfer rates are calculated to allow full and exact simulation of the dispersed fluorescence spectral profile using an iterative fitting procedure of the experimental spectrum. In order to take into account the relevant levels, which are unknown, all levels located below $x^{5} F_{5}^{o}$ $\left(40257 \mathrm{~cm}^{-1}\right)$ are considered [40]. Furthermore, collisional transfers toward upper levels up to $42500 \mathrm{~cm}^{-1}$ have to be added because their contributions cannot be neglected. Finally, 146 energy levels are put into the model, yielding $n=$ 146 first-order coupled differential rate equations to solve Eq. (1) with a total of 2001 transitions.

\section{Simulation and Fitting Procedure}

In the simulation of the experimental spectrum, the gaseous environment is assumed to be (in molar fraction): $\mathrm{He}(50.4 \%)$, $C_{3}(44.8 \%), C_{2}(3.0 \%), C(1.7 \%), \mathrm{Fe}(0.1 \%)$ [21]. For $\mathrm{He}$ noble gas, the quenching efficiency is known to be small [33] compared with molecular colliders. Furthermore, $C_{2}, C$, and Fe colliders are in small concentrations, so only $C_{3}$ radicals are considered to induce collisional transfers. In order to calculate the collisional cross section between the radiating iron atom and the $C_{3}$ radical, we consider a radius for the $\mathrm{Fe}$ atom, $r_{\mathrm{Fe}}=$ $132 \mathrm{pm}$ [41], and a radius for $C_{3}, r_{\text {pert }}=293 \mathrm{pm}$ [42]. For practical reasons, we use a steric factor $q$ averaged over all levels in order to calculate the collisional transfer rates $Q$ with Eqs. (3) and (4). The resulting $Q$ rates are then injected into Eq. (1) to calculate the population density of levels and reproduce the experimental spectra. The steric factor $q$ is adjusted to fit the experimental spectrum; it is the only adjustable parameter (from 0 to 1 ) in the present simulation. When it is increased, collisional transfers are more important, more 
states are populated by collisions, and the cascade (indirect) fluorescence becomes stronger.

The fitting procedure yields a factor $q=0.20$. Afterward, we estimate a total collisional transfer rate coefficient $k^{\text {tot }}$ to be $4,55 \times 10^{-10}$ molecule ${ }^{-1} \mathrm{~cm}^{-3} \mathrm{~s}^{-1}$ for the $x^{5} F_{5}^{o}$ state. This $k^{\text {tot }}$ value is of the same order of magnitude as the coefficient rates from [33] for molecular colliders and from [18] (see Table 2). We then calculate a total collisional transfer rate $Q^{\text {tot }}=4.94 \times 10^{8} \mathrm{~s}^{-1}$ at $2000 \mathrm{~K}$ and $300 \mathrm{hPa}$. At $1 \mathrm{MPa}$, $Q^{\text {tot }}$ rises to $1.65 \times 10^{9} \mathrm{~s}^{-1}$.

The simulated spectrum is presented in Fig. 6 together with the experimental one. The transitions involved in our dispersed fluorescence spectrum are determined from the model and the iterative fitting procedure compared with the energy levels scheme of Fig. 5, i.e., much more levels are involved (Fig. 7).

Fluorescence mainly arises from 47 transitions involving 19 energy levels belonging to four multiplet states with $y^{5} P^{o}, x^{5} D^{o}$, and $y^{5} G^{o}$, which are populated through collisional redistribution.

From the fitting procedure used in Fig. 6, we can note that all the spectral contributions are reproduced in the entire spectral domain with the steric factor adjusted to 0.20 , as mentioned above. The calculated intensity ratio of the strongest lines $(248 \mathrm{~nm} / 300 \mathrm{~nm})$ is consistent with the measured experimental ratio (equal to 18 including collisions instead of 25 without collisions). The shoulders at $250 \mathrm{~nm}$ and at 305$310 \mathrm{~nm}$ are also matching the observed ones. On the other hand, the $275 \mathrm{~nm}$ line is overestimated by a factor of 3 . This mismatch is probably due to our simple collisional model. One obvious limitation is that we do not fully discriminate the electronic configuration (quantum number $J$ ) of states in the collisional redistribution process [18,33,34]. Another limitation is the activation energy $\Delta E_{a}$, whose value is simply taken as the energy gap between the final and initial levels, which is probably underestimated [39]. The steric factor $q$ should account for these limitations, but, because an averaged value is used, this correction is not as accurate as it could be. Another important point is the influence of the saturation effect on the intensity distribution of the lines in the spectrum. As discussed later, specific attention has been paid to record the spectrum with a laser energy, which is low enough to prevent

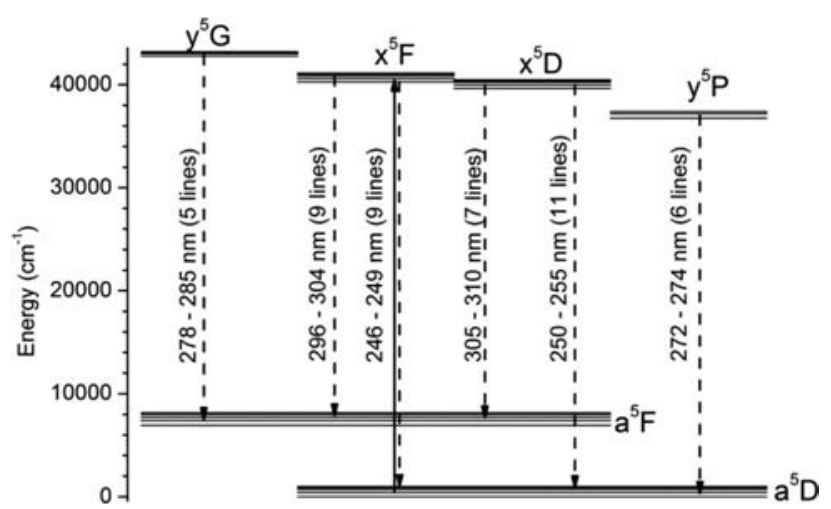

Fig. 7. Reduced energy-level scheme involved in the calculated fluorescence spectrum of Fig. 7. Laser excitation is indicated by a solid line. The fluorescence pathways are indicated by the dashed lines and include 47 transitions and 19 levels. the signal from being too strongly saturated. Furthermore, it is well known that the calculation of the saturation behavior of the LIF signal is not straightforward $[40,43]$.

For propellant flames application, laser scattering by particles may become important, so that discriminating an iron fluorescence signal from laser scattering at $\sim 248 \mathrm{~nm}$ will be delicate. Therefore, a detection window at $300 \mathrm{~nm}$ is preferentially chosen, although not as strong as the transition at $248 \mathrm{~nm}$ because a larger signal-to-noise ratio is expected in this range.

\section{Saturation Process and Sensitivity}

Laser energy is strongly attenuated down to a few $\mu \mathrm{J}$ per pulse. Saturation effects are expected due to the high absorption rate of the iron transition at $248.327 \mathrm{~nm}$ (Fig. 3). Saturation is strongly dependent upon laser characteristics (spatial, temporal, and spectral energy distributions), transition moment, and pressure (through collisional relaxation phenomena). In Fig. 8, the Fe signal is recorded versus laser energy and plotted in log-log scale [20]. Calibrated filters (Schott, UG5) are inserted into the laser beam path to quantitatively attenuate the total input energy. The slope of the curve is drawn from the $\log -\log$ plot.

At low energy $(<3 \mu \mathrm{J})$, the slope is 0.73 . The signal is thus already slightly saturating because linear dependence is not observed. Above $3 \mu \mathrm{J}$, the slope is smaller (0.4), indicating that saturation becomes stronger. The intersection between the two lines roughly corresponds to the saturation threshold $(S=1$ [40]). It gives a saturation threshold $E_{\text {las }}=3 \mu \mathrm{J}$ corresponding to a laser power density $I_{\text {las }}=10 \mathrm{~kW} / \mathrm{cm}^{2}$. Let us recall that only part of the input laser energy is effectively exciting the atomic line. The signal never reaches full saturation as often observed mainly because spatial distribution inside the laser spot $(6 \mathrm{~mm} \times 6 \mathrm{~mm})$ is not homogeneous at the probe volume (spatially averaged). The saturation curve of Fig. 8 is thus specific to our experimental conditions (geometry, linewidths). The saturation onset is always expected to increase with pressure because saturation is reduced when collisional transfers increase [43]. A complete model including saturation is detailed in $[20]$.

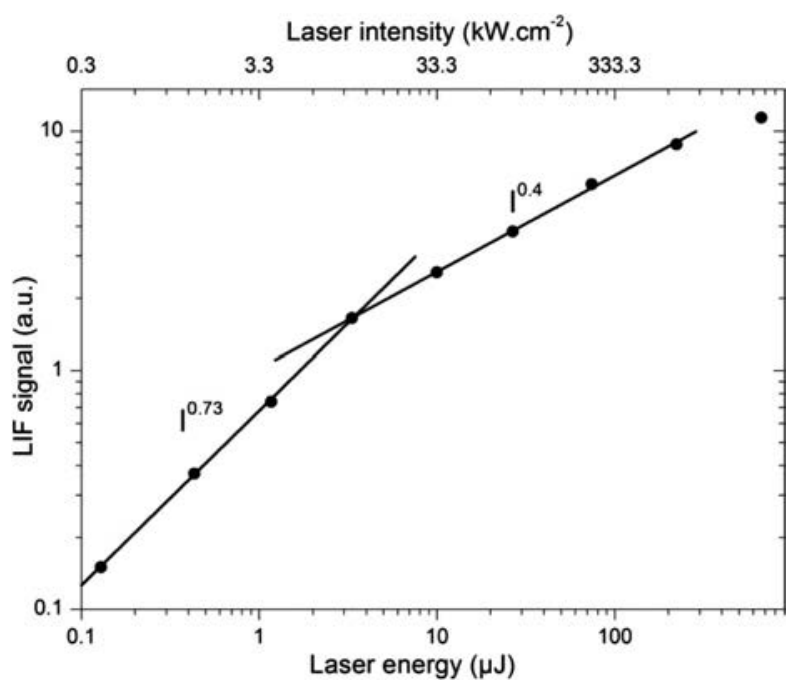

Fig. 8. Signal intensity as a function of laser energy at $248 \mathrm{~nm}$ in the same conditions as in Fig. 6. 


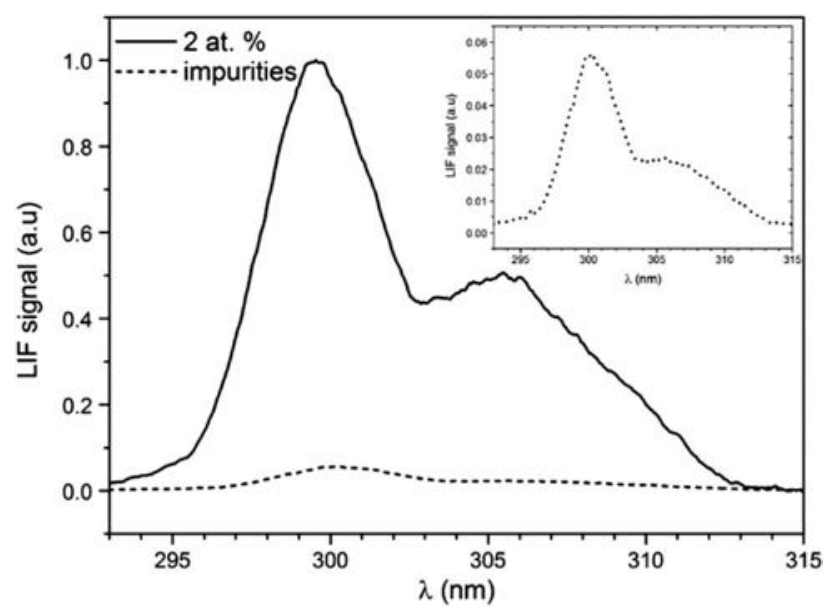

Fig. 9. Iron fluorescence lines around $300 \mathrm{~nm}$ are compared for two different concentrations of iron in the same operating conditions. A Fe-doped carbon target ( 2 at. \%) is probed in a solid line, and a carbon target containing iron impurities is shown in dotted lines. Iron impurities concentration is deduced from the measurement $(0.1$ at. \%).

Finally, in Fig. 9, fluorescence lines are recorded during laser vaporization of an iron-doped carbon target $(2$ at. \%) and a carbon target containing iron impurities (initial iron concentration is not known). Insight of the spectrum recorded in targets containing iron impurities is displayed on the top right corner. The ratio of intensities at $300 \mathrm{~nm}$ between both spectra gives the number density of iron impurities estimated to be at most 0.1 at. \%. The measurement illustrates that trace amounts of iron atoms are readily detected at high temperatures, if the above excitation/detection scheme is chosen.

\section{B. LIF Imaging in Propellant Flames}

In this section, images of the spatial distribution of $\mathrm{Fe}$ atoms are recorded above the surface of AP/HTPB propellants containing iron-based catalysts. The composite propellant is displayed as a gray rectangle to give an idea of its location in the image. The top of the rectangle roughly corresponds to the burning propellant surface. The proper position of the surface is known when the propellant is burning.

The mapping is represented in terms of counts (dynamic range: $0-65535$ counts). The fluorescence signal equal to zero is black, and color scales are displayed on each figure. The experiments were done in the flame burning at 0.3 and $1 \mathrm{MPa}$ and $2500 \mathrm{~K}$.

Considering the area of the laser sheet $(2.5 \mathrm{~mm} \times 16 \mathrm{~mm})$, the laser power density at the probe volume is estimated to be $2 \mathrm{MW} / \mathrm{cm}^{2}\left(E_{\mathrm{las}}=4 \mathrm{~mJ}\right.$ and pulse duration: $\left.5 \mathrm{~ns}\right)$. In this experiment, this value can be discussed with respect to the presented estimation of saturating conditions. At 1.0 MPa (propellant flames), the pressure has increased by a factor of 33 with respect to the vaporization reactor $(0.03 \mathrm{MPa})$. The saturation threshold is thus shifted toward higher $I_{\text {las }}$ due to larger collisional transfer rates. Therefore, a larger power density is used in that experiment to compensate for the signal loss.

Figure 10 shows a PLIF image recorded with AP/HTPB/ Fe-C propellant in a normal burning flame (without additional air flow) (Run 2 in Table 1).

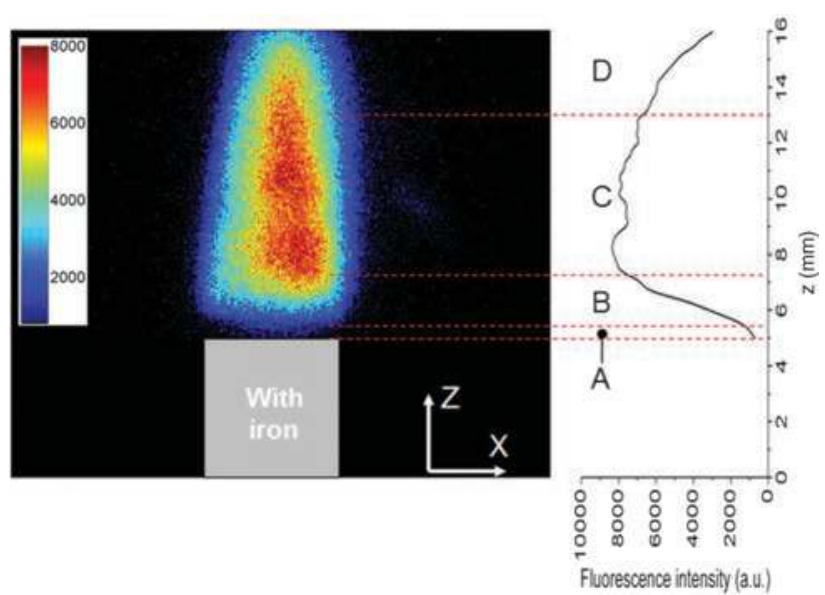

Fig. 10. Fe-PLIF image recorded above the surface of a burning $\mathrm{AP} / \mathrm{HTPB}$ propellant containing $\mathrm{Fe}-\mathrm{C}$ nanoparticles at $0.3 \mathrm{MPa}$ (Run 2). Vertical profile of the fluorescence is retrieved from the image intensity (on the right-hand side). Size of the image: $20 \mathrm{~mm} \times 16 \mathrm{~mm}$.

The laser sheet is crossing the flame from right to left in the image. The propellant formulation is a trimodal AP particle size distribution (coarse/medium/fine AP particles) with a load of 82 wt. \%. Fe-C nanoparticles are incorporated into the formulation as a catalyst with a $0.5 \mathrm{wt}$. \% iron content. LIF signals are spread homogeneously above the propellant surface and are only due to $\mathrm{Fe}$ atoms. No signal is observed when the laser is switched off. A gradient of signal is recorded along the vertical direction from which a profile is extracted (right of Fig. 10). It is recorded on the $Z$ axis of the flame, in its central region. The first region immediately above the propellant surface (named A in Fig. 10) has low fluorescence intensity up to $400 \mu \mathrm{m}$. Then, the signal rises over $2 \mathrm{~mm}$ (region B in Fig. 10) to reach a constant level (7000-8000 counts) with a signal-to-noise ratio of the order of 1700 . A signal is persistent over $6 \mathrm{~mm}$ corresponding to region $C$ in Fig. 10. Finally, the signal decreases to less than 3000 counts at $z=16 \mathrm{~mm}$, due to slow cooling of the gas (region D in Fig. 10). The first rise of the signal in region B results from a temperature increase with ignition. Indeed, the temperature of the propellant surface (where $\mathrm{Fe}-\mathrm{C}$ nanoparticles are released) is of the order of 700-900 K because the decomposition of AP starts at $\sim 520 \mathrm{~K}$, and its melting temperature is $835 \mathrm{~K}$ according to $[44,45]$. Let us note that it is significantly lower than the melting temperature of iron (1811 K) because nanoparticles are melting at lower temperature [21]. Higher on the vertical axis, temperature rapidly increases to overpasses $2000 \mathrm{~K}$ in the flame zone [26]. Iron atoms evaporation appears enhanced when nanoparticles carried by the flow are melting. The thickness of region $\mathrm{A}$ is in agreement with Gross and Beackstead results [26].

Finally, the radial distribution of Fe atoms along the $X$ axis is also plotted in Fig. 10. It is a slightly asymmetric profile, which is resulting from laser absorption over the flame width ( $\sim 5 \mathrm{~mm}$, from right to left).

Investigation of the flow structure is now performed above the surfaces of two AP/HTPB propellants. The geometry is chosen to maximize turbulence apparition. First, lateral air flow 
is injected at flow velocity is $5 \mathrm{~m} / \mathrm{s}$ for both 0.3 and $1.0 \mathrm{MPa}$ in order to induce turbulent structures. The samples are side by side at the bottom of the chamber and burning simultaneously. One propellant is doped with iron-based catalysts, and the other is not [Fig. 1(b)]. Moreover, samples heights are different in creating a step (height: 4 and $6 \mathrm{~mm}$ ) because the aim is to generate a shear layer subsequently leading to vortices in the flow. The doped sample is ignited by the $\mathrm{CO}_{2}$ laser. The air flow and the laser are counter propagating.

In Fig. 11, two single-shot images are recorded on the burning AP/HTPB propellants (with and without iron) for the conditions of Run 3 (see Table 1).

The left propellant is doped with $\mathrm{Fe}-\mathrm{C}$ nanoparticles (1.23 wt. \% iron). The top image is recorded $1.5 \mathrm{~s}$ after the ignition (at half the duration of the combustion sequence). The bottom image is recorded at the end of the combustion sequence. In opposition to Fig. 10 recorded in a quiescent atmosphere, the flame is bent due to the lateral air flow. It definitely shows that the Fe-LIF signal is only present above the iron-doped propellant. Indeed, the interface between hot gases generated by the flame on each propellant is clearly visible. At this location, the signal sharply reduces from a large level, down to zero above the iron-free propellant. The signal reaches a two times higher signal in Fig. 11 than in Fig. 10, due to increase of iron content from 0.5 to 1.23 (from Run 2 to 3 ). Large-scale flow structures can be observed on the image, due to the gradual vanishing of the laminar boundary layer between the cold flow and hot flame gases. Shear stress generates coherent structures. A typical turbulent structure, called a "vortex" (with two counter-rotating vortices) are observed on the righthand side of the image. Iron atom accumulation is observed in

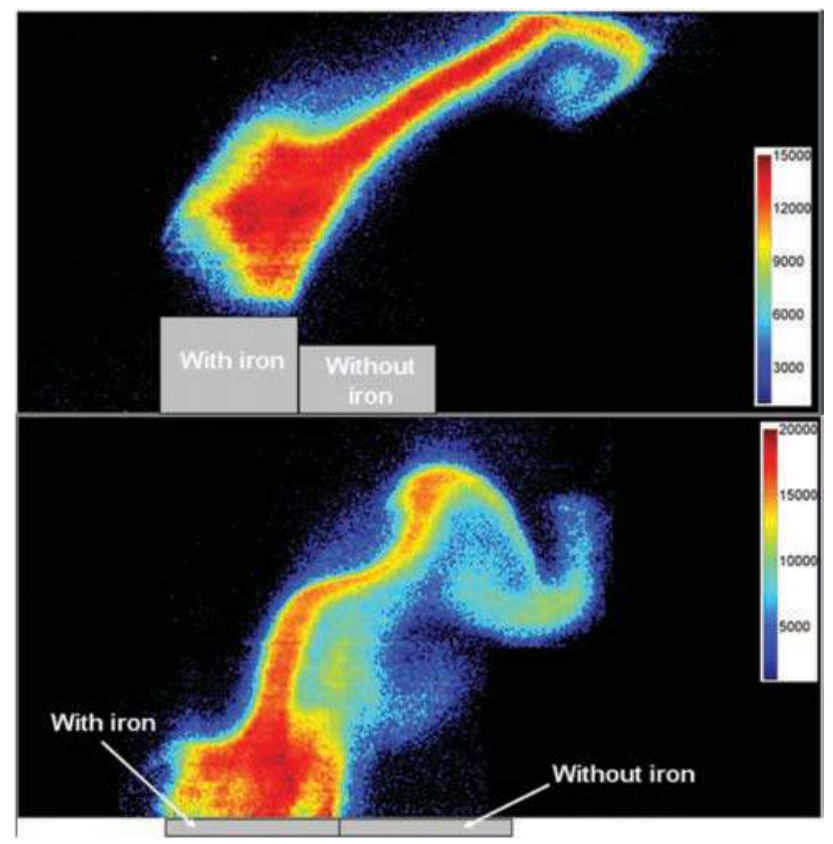

Fig. 11. Fe-PLIF images recorded above the surfaces of burning $\mathrm{AP} / \mathrm{HTPB}$ propellants with and without $\mathrm{Fe}-\mathrm{C}$ nanoparticles at $0.3 \mathrm{MPa}$ (Run 3). Size of the image is $30 \mathrm{~mm} \times 16 \mathrm{~mm}$. Top image is recorded $1.5 \mathrm{~s}$ after ignition, and bottom image is recorded at the end of the combustion. the "vortex head," whereas fluorescence intensity is reduced due to air dilution. Such image demonstrates that Fe atoms are diluted but still observed at the periphery of the large-scale structures. Of course, the short gate (50 ns) of the ICCD camera enables us to sketch the flow pattern. This was the objective of these imaging experiments. However, the low repetition rate of the camera $(3 \mathrm{~Hz})$ does not allow the resolution of the temporal evolution of the vortices.

Figure 12 displays a Fe-PLIF image recorded at $1.0 \mathrm{MPa}$ (Run 4 of Table 1) at half the duration of the combustion sequence ( $1.5 \mathrm{~s}$ in total). In this case, propellants contain $0.5 \mathrm{wt}$. $\%$ of iron, as in Fig. 10, but 2.5 less than in Fig. 11. In Fig. 12, the Fe-LIF signal is twice less that in Fig. 11, although pressure has increased from $0.3 \mathrm{MPa}$ to $1 \mathrm{MPa}$ and iron content is 2.5 times less in the propellant.

Therefore, signal to noise is observed to stay in the same range between 0.3 and $1 \mathrm{MPa}$. At this point, we assume that the saturation threshold may be located around 0.3 MPa. Indeed, our observation reveals that, although signal decreases with pressure with respect to collisional transfers, the signal decrease is compensated. When pressure increases beyond $0.3 \mathrm{MPa}$, the saturation is vanishing and signal dependence versus pressure changes rapidly. Therefore, instead of a signal decrease with quenching, the signal value is maintained at $1 \mathrm{MPa}$, as already observed between 0.05 and $0.1 \mathrm{MPa}$ in aluminum [20].

Moreover, the vaporization process is observed to change. A slightly higher vaporization rate is achieved at $1 \mathrm{MPa}$, leading to an increase in iron number density in the gas phase [26] because a faster surface regression is measured at 1.0 MPa. As a result, the spatial extent of iron vapor is larger, whereas air flow velocity is kept constant at whatever pressure. Also, when pressure increases, the height of the flame rapidly decreases.

Finally, Fe-PLIF is tested with a couple of AP/Al/HTPB/ butacene and $\mathrm{AP} / \mathrm{HTPB} /$ butacene propellants (Fig. 13) at 1.0 MPa.

The mass fraction of iron is nearly $0.1 \%$ in both propellants (Run 5 in Table 1), whereas both micro- and nanoparticles (17 wt. \%) of aluminum are added to one sample only. The image is recorded late in the combustion sequence (duration $2.5 \mathrm{~s}$ ), i.e., $1.9 \mathrm{~s}$ after the ignition. The double sample image is demonstrating the sensitivity of atom diagnostics at low concentration, suggesting that the technique will be efficient far

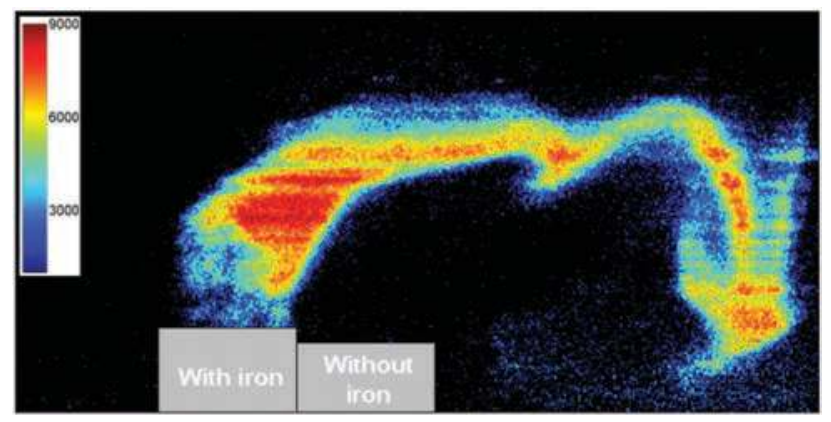

Fig. 12. Fe-PLIF image recorded above the surfaces of burning AP/ $\mathrm{HTPB}$ propellants with and without $\mathrm{Fe}-\mathrm{C}$ nanoparticles at $1.0 \mathrm{MPa}$ (Run 4). Image is recorded $0.75 \mathrm{~s}$ after ignition. Image size as in Fig. 11. 


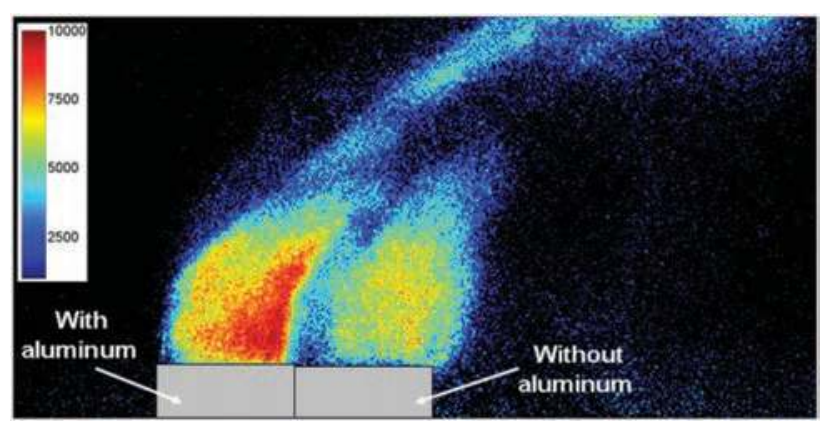

Fig. 13. Fe-PLIF image recorded above the surfaces of $\mathrm{AP} / \mathrm{Al} /$ $\mathrm{HTPB} /$ butacene and $\mathrm{AP} / \mathrm{HTPB} /$ butacene propellants at $1.0 \mathrm{MPa}$ (Run 9). Image size as in Fig. 11.

above $2 \mathrm{MPa}$. The signal level is even higher above the aluminized propellant (sample on the left in Fig. 13) because a higher temperature is reached (i.e., $\sim 3400 \mathrm{~K}$ versus $\sim 2500 \mathrm{~K}$ without aluminum at $1.0 \mathrm{MPa}$ [45]). The surface heat flux is crucial because it drives the decomposition of the condensed phase of the propellant. As a result, the regression rate of the propellant surface is higher with a combustion velocity of $10 \mathrm{~mm} / \mathrm{s}$ for aluminized propellant as opposed to $7 \mathrm{~mm} / \mathrm{s}$ for the nonaluminized one. Mass flow rate of Fe atoms evaporated due to the butacene thermal decomposition being larger, too. Finally, we can see that the interface between the two flows has a lower signal intensity in which iron is not present probably because the flow is upward.

\section{CONCLUDING REMARKS}

In this paper, our purpose is to contribute to the analysis of the propellant flame structure by using iron fluorescence for interesting applications. Our study first aims at demonstrating the potential of Fe-PLIF to visualize the aerodynamic flow field in solid propellant combustion. This suggests the particular ability of the technique to follow the spatial/temporal evolution of flow structures (vortices, flapping, etc.) that may appear in hot gases and sometimes to preclude them if necessary. The Fe-PLIF is shown to be well suited to visualize flame structures such as vortices in burning propellants.

In addition, careful spectroscopic investigation is undertaken so as to perform accurate measurements. An adequate excitation/detection scheme was chosen. Dispersed fluorescence measurements are carried out in a hot and nonreactive flow to validate our diagnostic strategy by exciting at $248 \mathrm{~nm}$ and detecting fluorescence at $300 \mathrm{~nm}$. A full calculation of iron fluorescence signal intensity is carried out thanks to several assumptions, allowing us to reduce the final number of levels effectively used in the spectral simulation. The fit of the experimental spectrum with theoretical profile allow us to determine the states and cascade transitions, which are mainly contributing to the iron fluorescence.

Atomic iron is a suitable tracer to probe the combustion process of solid propellants containing iron-based catalysts. Thanks to its high fluorescence yield, sensitivity is high, although the losses induced by the pressure effects. Our model was therefore able to estimate the collisional energy transfers and their influence on the intensity distribution of the direct and indirect fluorescence lines. This model involves a large number of levels to be able to reproduce the collisional redistribution of the density population of the levels. This calculation will be used to allow quantitative analysis of the images and of Fe concentration in combustion environments.

Finally, experiments have demonstrated that iron fluorescence signals can be easily detected at pressures up to $1.0 \mathrm{MPa}$. In real conditions of propellant combustion, fluorescence signals originating from iron atoms remain strong at $1.0 \mathrm{MPa}$ even with low concentration of iron $(<0.1 \%)$; as shown in our measurements, we assume that measurements at $1 \mathrm{MPa}$ are recorded in a quasi-linear regime.

Another prospect concerns the development of Fe-PLIF to investigate the flow structure at a microscopic scale close the surface of a burning propellant, e.g., to study the effect of iron additives on combustion properties (regression velocity, propellant surface behavior, etc.). Fe-PLIF can be used to investigate the flow structure because, in opposition to $\mathrm{Al}[20,39]$, it is not a reactant and is easily flown in the vortices merely according to temperature gradients. Our experimental data may contribute to the better understanding of flame behavior under highpressure conditions. In the future, it will also be necessary to increase the repetition rate to $\mathrm{kHz}$ values to allow better sampling of the fast flame events or flow dynamic.

Funding. Direction Générale de l'Armement (DGA); ONERA.

\section{REFERENCES}

1. T. Parr and D. Hanson-Parr, "Nonintrusive diagnostic techniques for research on nonsteady burning of solid propellants," in Nonsteady Burning and Combustion Stability of Solid Propellants (American Institute of Aeronautics and Astronautics, 1992), pp. 261-324.

2. T. Parr and D. Hanson-Parr, "Optical diagnostics of solid-propellant flame structures," in Solid Propellant Chemistry, Combustion, and Motor Interior Ballistics (American Institute of Aeronautics and Astronautics, 2000), pp. 381-411.

3. T. Edwards, D. P. Weaver, D. H. Campbell, and S. Hulsizer, "Investigation of high pressure solid propellant combustion chemistry using emission spectroscopy," J. Propul. Power 2, 228-234 (1986).

4. D. H. Campbell, S. Hulsizer, T. Edwards, and D. P. Weaver, "Solid propellant combustion zone structure from analysis of hydroxyl radical chemiluminescence," J. Propul. Power 2, 414-422 (1986).

5. Y.-C. Lu, T. Freyman, and K. K. Kuo, "Measurement of temperatures and $\mathrm{OH}$ concentrations of solid propellant flames using absorption spectroscopy," Combust. Sci. Technol. 104, 193-205 (1995).

6. B. E. Homan, M. S. Miller, and J. A. Vanderhoff, "Absorption diagnostics and modeling investigations of RDX flame structure," Combust. Flame 120, 301-317 (2000).

7. S. H. Modiano and J. A. Vanderhoff, "Multichannel infrared absorption spectroscopy of solid propellant flames," Combust. Flame 99, 187-189 (1994).

8. C. F. Mallery and S. T. Thynell, "Line-of-Sight Variations of Temperature and Species in Solid Propellant Flames," J. Propul. Power 16, 505-512 (2000).

9. T. Parr and D. Hanson-Parr, "Cyclotetramethylene tetranitramine/ glycidyl azide polymer/butanetriol trinitrate propellant flame structure," Combust. Flame 137, 38-49 (2004).

10. K. Aron and L. E. Harris, "CARS probe of RDX decomposition," Chem. Phys. Lett. 103, 413-417 (1984).

11. J. H. Stufflebeam and A. C. Eckbreth, "CARS diagnostics of solid propellant combustion at elevated pressure," Combust. Sci. Technol. 66, 163-179 (1989) 
12. T. Edwards, D. P. Weaver, and D. H. Campbell, "Laser-induced fluorescence in high pressure solid propellant flames," Appl. Opt. 26, 3496-3509 (1987).

13. T. Parr and D. Hanson-Parr, "RDX ignition flame structure," Symp. Int. Combust. 27, 2301-2308 (1998).

14. T. Parr, D. Hanson-Parr, M. Smooke, and R. Yetter, "Laser diagnostic measurement of solid propellant flame structure for model validation," in 21st Aerodynamic Measurement Technology and Ground Testing Conference (American Institute of Aeronautics and Astronautics, 2000).

15. T. D. Hedman, K. Y. Cho, A. Satija, L. J. Groven, R. P. Lucht, and S. F. Son, "Experimental observation of the flame structure of a bimodal ammonium perchlorate composite propellant using $5 \mathrm{kHz}$ PLIF," Combust. Flame 159, 427-437 (2012).

16. T. D. Hedman, L. J. Groven, R. P. Lucht, and S. F. Son, "The effect of polymeric binder on composite propellant flame structure investigated with 5 kHz OH PLIF," Combust. Flame 160, 1531-1540 (2013).

17. K. Kitagawa, S. Itoh, N. Arai, and A. K. Gupta, "Profiling of redox atmosphere in flames by chemical seeding/planar laser-induced fluorescence (CS/PLIF)," J. Eng. Gas Turbines Power 128, 765-772 (2005).

18. C. Hecht, H. Kronemayer, T. Dreier, H. Wiggers, and C. Schulz, "Imaging measurements of atomic iron concentration with laserinduced fluorescence in a nanoparticle synthesis flame reactor," Appl. Phys. B 94, 119-125 (2009).

19. G. Avalon, B. Ugurtas, F. Grisch, and A. Bresson, "Numerical computations and visualization tests of the flow inside a cold gas simulation with characterization of a parietal vortex shedding," in 36th AIAA/ ASME/SAE/ASEE Joint Propulsion Conference and Exhibit (American Institute of Aeronautics and Astronautics, 2000).

20. G. Vilmart, N. Dorval, B. Attal-Tretout, and A. Bresson, "Detection of iron and aluminum atomic vapors by LIF technique: application to solid propellant combustion," in 33rd AIAA Aerodynamic Measurement Technology and Ground Testing Conference (American Institute of Aeronautics and Astronautics, 2017).

21. M. Cau, N. Dorval, B. Attal-Trétout, J.-L. Cochon, A. Foutel-Richard, A. Loiseau, V. Krüger, M. Tsurikov, and C. D. Scott, "Formation of carbon nanotubes: In situ optical analysis using laser-induced incandescence and laser-induced fluorescence," Phys. Rev. B 81, 165416 (2010).

22. N. Dorval, A. Foutel-Richard, M. Cau, A. Loiseau, B. Attal-Trétout, J. L. Cochon, D. Pigache, P. Bouchardy, V. Krüger, and K. P. Geigle, "In-situ optical analysis of the gas phase during the formation of carbon nanotubes," J. Nanosci. Nanotechnol. 4, 450-462 (2004).

23. F. Cauty, "Investigation in energetic materials combustion: a strategy for numerical simulation validation," in 42nd AIAA/ASME/SAE/ASEE Joint Propulsion Conference \& Exhibit (American Institute of Aeronautics and Astronautics, 2006).

24. Internal R\&D Program at ONERA on Nano-Sized Catalysts for Solid Propellant Flames Applications (n.d.).

25. "Atomic spectral line database from CD-ROM 23 of R. L. Kurucz," https://www.cfa.harvard.edu/amp/ampdata/kurucz23/sekur.html.
26. M. L. Gross and M. W. Beckstead, "Diffusion flame calculations for composite propellants using a vorticity-velocity formulation," J. Propul. Power 25, 74-82 (2009).

27. J. Luque and D. R. Crosley, LIFBASE: Database and Spectral Simulation Nersion 2.1.1) (SRI International, 2014).

28. R. W. B. Pearse and A. G. Gaydon, "The identification of molecular spectra," J. Chem. Educ. 41, A398 (1964).

29. J. M. Delaval, C. Dufour, and J. Schamps, "Rotational analysis of ultraviolet systems of FeCl," J. Phys. B 13, 4757-4769 (1980).

30. J. Lei and P. J. Dagdigian, "Molecular beam study of the ${ }^{6} \Pi-X^{6} \Delta$ electronic transition in FeCl," J. Chem. Phys. 112, 10221-10227 (2000).

31. J. W. Daily, "Laser induced fluorescence spectroscopy in flames," Prog. Energy Combust. Sci. 23, 133-199 (1997).

32. R. C. Hilborn, "Einstein coefficients, cross sections, $f$ values, dipole moments, and all that," Am. J. Phys. 50, 982-986 (1982).

33. B. Nizamov and P. J. Dagdigian, "Collisional quenching and energy transfer of the $z^{5} D_{\jmath}{ }^{\circ}$ states of the Fe atom," J. Phys. Chem. A 104, 6345-6350 (2000).

34. J. S. Goo, K. Lee, S. C. Bae, and J. K. Ku, "Collisional mixing among the $z^{3} D_{J}$ and $z^{3} F_{J}$ states of $\mathrm{Fe}$ atoms in $\mathrm{He}$ and $\mathrm{Ar}$, " J. Chem. Phys. 105, 7485-7494 (1996).

35. J.-M. Hartmann, C. Boulet, and D. Robert, "II-General Equations," in Collisional Effects on Molecular Spectra (Elsevier, 2008), pp. 9-62.

36. J. B. Foresman and Ae. Frisch, Exploring Chemistry with Electronic Structure Methods: A Guide to Using Gaussian (Gaussian, Incorporated, 1993).

37. P. Atkins and J. de Paula, Atkins' Physical Chemistry (OUP Oxford, 2010).

38. C. T. J. Alkemade, T. Hollander, W. Snelleman, and P. J. T. Zeegers, Metal Vapours in Flames (Elsevier, 2013).

39. G. Vilmart, Détection de vapeurs d'atomes métalliques par Fluorescence Induite par Laser (LIF): Application à la propulsion solide (Paris-Saclay, 2017).

40. B. Cordero, V. Gómez, A. E. Platero-Prats, M. Revés, J. Echeverría, E. Cremades, F. Barragán, and S. Alvarez, "Covalent radii revisited," Dalton Trans., 2832-2838 (2008).

41. P. J. Linstrom and W. G. Mallard, NIST Chemistry WebBook, NIST Standard Reference Database Number 69 (National Institute of Standards and Technology, 2017).

42. C. T. J. Alkemade, "Anomalous saturation curves in laser-induced fluorescence," Spectrochim. Acta B 40, 1331-1368 (1985).

43. C. Guirao and F. A. Williams, "A model of ammonium perchlorate deflagration between 20 and 100 atm," AIAA J. 9, 1345-1356 (1971).

44. M. W. Beckstead, R. L. Derr, and C. F. Price, "The combustion of solid monopropellants and composite propellants," Symp. Int. Combust. 13, 1047-1056 (1971).

45. E. B. Washburn, J. N. Trivedi, L. Catoire, and M. W. Beckstead, "The simulation of the combustion of micrometer-sized aluminum particles with steam," Combust. Sci. Technol. 180, 1502-1517 (2008). 